\title{
Using a Modified Intervention Mapping Approach to Develop and Refine a Single-Session Motivational Intervention for Methamphetamine-Using Men Who Have Sex With Men
}

\author{
William A. Zule ${ }^{*}$, Curtis M. Coomes, Rhonda Karg, Jennie L. Harris, Alex Orr and \\ Wendee M. Wechsberg
}

\author{
Behavioral Health and Criminal Justice Research Division, RTI International, 3040 Cornwallis Rd., Research Triangle \\ Park, NC 27709-2194, USA
}

\begin{abstract}
There is an ongoing need for the development and adaptation of behavioral interventions to address behaviors related to acquisition and transmission of infectious diseases and for preventing the onset of chronic diseases. This paper describes the application of an established systematic approach to the development of a behavioral intervention to reduce sexual risk behaviors for HIV among men who have sex with men and who use methamphetamine. The approach includes six steps: (1) a needs assessment; (2) preparing matrices of proximal program objectives; (3) selecting theory-based methods and practical strategies; (4) producing program components and materials; (5) planning for program adoption, implementation, and sustainability; and (6) planning for evaluation. The focus of this article is on the intervention development process; therefore the article does not describe steps 5 and 6. Overall the process worked well, although it had to be adapted to fit the sequence of events associated with a funded research project. This project demonstrates that systematic approaches to intervention development can be applied even in research projects where some of the steps occur during the proposal writing process rather than during the actual project. However, intervention developers must remain flexible and be prepared to adapt the process to the situation. This includes being ready to make choices regarding intervention efficacy versus feasibility and being willing to select the best intervention that is likely to be delivered with available resources rather than an ideal intervention that may not be practical.
\end{abstract}

Keywords: Intervention development, intervention mapping, motivational interviewing, formative work, methamphetamine.

\section{INTRODUCTION}

Methamphetamine (MA) use is common in many parts of the United States among men who have sex with men (MSM) [1]. Colfax and colleagues [2] reported use of MA and similar stimulants to be 10 times higher among MSM than among the general population. Rates among young MSM and those who attend circuit parties are even higher [3-5]. MA use among MSM has been associated with a variety of high-risk sexual activities [6-9] as well as prevalent $[10,11]$ and incident HIV infections $[12,13]$. MA use has been associated with higher frequencies of unprotected anal intercourse (UAI) among users [14]. Evidence suggests that it increases sexual drive and decreases inhibitions [15], potentially doubling or tripling the probability of high-risk encounters and sexually transmitted infection acquisition $[3,16,17]$. The combination of increased physical stimulation and reduction of inhibitions has been associated with longer periods of sexual intercourse, greater frequency of group sex, and more extreme sexual behaviors, such as "fisting" [18] and condom

*Address correspondence to this author at the Behavioral Health and Criminal Justice Research Division, RTI International, 3040 Cornwallis Rd., Research Triangle Park, NC 27709-2194, USA; Tel: 919-485-2797; E-mail: zule@rti.org

${ }^{\S}$ RTI International is the trade name of Research Triangle Institute. breakage [19]. MA use is also associated with high numbers of sexual partners, decreased condom use, and polydrug use [20,21], which further exacerbate HIV risk.

The current MA epidemic among MSM began in urban areas in the western United States and spread to the East Coast in the late 1990s [22, 23]. In a national online survey of 2,916 MSM, $16 \%$ of men from the South Atlantic region, which extends from Maryland to Florida, reported using MA [24]. Although there have been a number of studies of MA use among heterosexuals outside of major urban areas in the South [25] and other parts of the United States, most studies of MA use among MSM have been in major urban centers. Nonetheless, one recent study from North Carolina found that $6 \%$ of MSM had used MA within the last 30 days [26].

\section{Local Context}

The Raleigh-Durham-Cary Combined Statistical area includes 8 counties that cover 4,476 square miles with a total population of 1.69 million people. Approximately 1.3 of the 1.69 million people live in the Raleigh-Cary and the DurhamChapel Hill metropolitan areas within the combined statistical area. There are several 'gay bars' and a 'gay bookstore' in the city of Raleigh, but there is no concentrated 'gay district' anyplace in the entire area. Although MA use among MSM is present, it is highly stigmatized and there are no services specifically for MSM that use MA. North Carolina enacted a law in March 2005 that was amended in July 2006, which 
restricted access to cold medications that contained pseudoephedrine, a common precursor in the manufacture of methamphetamine. The formative work described in this paper was conducted, in 2006 and 2007. In conjunction with the passage of the law, efforts by local law enforcement to target methamphetamine distributors increased. These actions resulted in some temporary decreases in the availability of MA in the area and they also drove local MA users even deeper underground, which complicated the intervention development process by reducing access to the target population. Similar situations are likely to be encountered in other smaller urban areas across North Carolina and the southeastern United States.

This paper describes the development process of an intervention for MA-using MSM in the Raleigh-DurhamCary Combined Statistical area.

\section{METHODS}

\section{Intervention Development Process}

We used a stepwise approach, loosely modeled after intervention mapping [27], to develop an intervention for MA-using MSM. Intervention mapping is a systematic approach to intervention development that is divided into five or six steps, depending on whether the needs assessment activities are considered a preliminary activity or a separate part of the process. The basic steps in intervention mapping are (1) a needs assessment; (2) preparing matrices of proximal program objectives; (3) selecting theory-based methods and practical strategies; (4) producing program components and materials; (5) planning for program adoption, implementation, and sustainability; and (6) planning for evaluation. Each step includes several tasks. As each task is completed the results of the completed task are used for the subsequent task. We describe steps 1 through 4 of the process in the following sections in this report.

\section{Step 1. Needs Assessment}

Our needs assessment was a three-step process that included (1) a review of the literature; (2) analyses of qualitative and quantitative data from two previous studies (i.e., the North Carolina site of the U.S. National Institute on Drug Abuse (NIDA)-funded Sexual Acquisition and Transmission Cooperative Agreement Program [NC SATHCAP] $[28,29]$ and the Chronic Hepatitis Intervention Project for Drug Users [CHIP] [30]) that included some MA-using MSM; and (3) collection of new data using focus groups and semi-structured interviews.

The primary purpose of the needs assessment was to (1) identify specific sexual risk behaviors associated with MA use among MSM, (2) determine which behaviors would be amenable to change, (3) identify the determinants of those behaviors, and (4) review interventions for MSM and for MAusing MSM in particular and determine the characteristics of interventions that were effective and feasible. Secondary objectives were to identify strategies for recruiting MA-using MSM in the area and to assess the characteristics of an intervention that would increase their participation in it. However, because of the focus on intervention development, findings regarding recruitment strategies are not described in this paper.

\section{Step 2. Matrix of Change Objectives}

In this step we held meetings with the research team, our community advisory board, and our consultants in which we discussed the findings from the needs assessment. We developed a list of behavioral determinants that were amenable to change, and we identified a list of change objectives.

\section{Step 3. Selecting Theoretical Methods and Strategies}

We compiled a list of possible strategies and methods from the literature and then held a brainstorming session to consider these and other methods and strategies for changing similar behaviors (i.e., decreasing unprotected intercourse, increasing condom use, and decreasing drug use) in other high-risk populations (e.g., injecting drug users, crack cocaine smokers). The purpose was to determine which methods and strategies would be appropriate for achieving the change objectives identified in step 2.

\section{Step 4. Designing an Intervention}

In this step, we translated the methods and strategies selected in step 3 into an intervention designed to achieve the behavior change objectives that we identified in step 2 . Findings from our previous work, knowledge of local conditions, focus groups and individual interviews influenced the choice of content (including change objectives) and the approach and format that we selected for delivering the intervention.

\section{Deviations from the Intervention Mapping Approach}

It is important to note that the intervention was developed in the context of a research project, which was designed in response to a funding opportunity. As such, the first phase of the needs assessment (i.e., problem identification) was conducted by the funder prior to the release of the request for applications. We did, however, conduct an environmental scan of local data sources to more accurately describe the scope of MA use among MSM in our area. A large portion of the needs assessment phase that identified determinants of sexual risk among MA-using MSM and potential theoretical methods and strategies for reducing that risk was conducted in the process of preparing the grant application. Accordingly, we selected our intervention approach prior to conducting focus groups and semistructured interviews with current and former MA users and local service providers that work with MA-using MSM. However, focus groups and semistructured interviews were conducted and the findings were used to revise and refine the intervention that we presented in our grant application. Consequently, the intervention development process included most of the steps in the intervention mapping process in roughly the order in which they are designed to occur.

\section{RESULTS}

\section{Step 1. Needs Assessment}

\section{Assessment of the Problem}

At the time of our literature review there were no published studies of MA use among MSM in North 
Carolina; however, our NC SATH-CAP study and the CHIP study both included a number of MSM who reported using MA. In semistructured interviews conducted during the formative phase of the NC SATH-CAP, 5 of 52 MSM reported current MA use and 3 others reported a history of use. We also found that $12 \%$ of 152 MSM (including bisexual men) enrolled during 2005 and 2006 in the main NC SATH-CAP study reported using MA in the previous 30 days [Zule, unpublished data]. In addition, current infection with syphilis, gonorrhea, or Chlamydia was $11 \%$ among MSM who reported MA use in the previous 30 days compared with $6 \%$ among those who had not used it.

\section{Identification of Risk Behaviors}

Findings from the literature review suggested that MA use was associated with engaging in unprotected anal intercourse (UAI) [14, 24]. One longitudinal study found that over a 4-year period, UAI was higher during periods of both light and heavy use of MA and other drugs (i.e., cocaine, poppers) compared with periods of no use [2]. The authors concluded that there may be no safe level of use of these drugs and interventions may need to focus on encouraging MSM to discontinue use of MA, poppers, and cocaine rather than reducing risk while using them.

As noted previously, $12 \%$ of MSM enrolled during the first year of the NC SATH-CAP reported using MA in the previous 30 days. Although the number of MA-using MSM was small $(n=19)$ compared with MSM who had not used MA in the previous 30 days, they were more likely to report UAI. Specifically, $47 \%$ of MSM who reported using MA in the previous 30 days reported insertive UAI while only $26 \%$ of those who had not used MA reported it. Rates of receptive UAI were also higher among MA-using MSM than among those who were not using it ( $32 \%$ vs $16 \%)$, and MA users were more likely than nonusers to report engaging in both receptive and insertive UAI ( $37 \%$ vs $17 \%)$. In addition to the NC SATHCAP, the CHIP study included event-level data from 155 MSM sexual encounters reported by 129 male injecting drug users. In 29 of those encounters one partner used MA and in 14 both partners used it. Unprotected anal intercourse was reported in $4 \%$ of encounters when no one used MA, $11 \%$ when one partner used it and in $15 \%$ of encounters when both partners used it.

\section{Findings from Focus Groups and Semistructured Interviews}

For the current study we conducted 3 focus groups and 10 semistructured interviews with service providers, former MA-using MSM, and current MA-using MSM. The focus group and semistructured interview guides are included as supplementary material. The 3 focus groups included a total of 13 participants - service providers $(n=5)$, former MA users $(n=4)$, and current MA users $(n=4)$. We also reviewed the 8 semistructured interviews, 3 with former and 5 with current MA-using MSM, that we conducted during the formative phase of the NC SATH-CAP.

Analysis of data from the focus groups and semistructured interviews with service providers, former MA users, and current MA users provided additional support for the occurrence of UAI among local MA-using MSM. According to participants in the provider focus group, most MA-using MSM in the area are white; nonetheless, they voiced concerns about MA moving into the local African American community. Providers felt that MA is a very social drug but also highly stigmatized, and as a consequence, users tend to use with other users while concealing their use from nonusers. They also felt that MA was involved in the party and play scene, which often involves anonymous meetings for sex set up through the Internet.

Providers felt that the ability of the interventionist to develop rapport with clients would be critical to the success of the intervention. As such they thought that the interventionist should be an MSM who was a former MA user. They felt that the intervention should focus on reducing sex risk rather than MA use. Providers also thought that a single- session intervention would be acceptable to most MA-using MSM.

While the former MA users agreed with the service providers on a number of issues, they also differed on a couple of important issues. Specifically, they felt that the intervention should focus on reducing MA use rather than sex risk because they did not believe that men could resist having unsafe sex while they were using MA. They also felt that a single-session intervention would be insufficient to reduce both MA and sex risk.

The current MA users had similar concerns regarding a single session; however, they thought that the intervention could be effective if men were given materials (e.g., educational materials, lists of resources, and condoms) to take with them. They also thought that the intervention would need to present men with a range of options for reducing their risk. They did not feel, for instance, that men who only use MA once every 2 months would be willing to stop using MA. For these men, they thought the intervention should focus on reducing unprotected sex when they do use MA. However, they did feel that men whose MA use was more frequent (e.g., several times a week) may be starting to experience problems and that they may be willing to consider reducing their MA use. For these men, they thought the intervention should focus on reducing MA.

\section{Intervention Feasibility}

Because there are no services in the area designed specifically for MA-using MSM, any intervention for MAusing MSM locally will have to be something that organizations that work with MSM in general or with drug users in general can easily incorporate into their current services. Most counselors at local substance abuse treatment programs and many counselors at local organizations that provide HIV counseling and testing have been trained in motivational interviewing. However, local service providers do not have the resources to provide the multi-session labor intensive interventions that are likely to be most efficacious in reducing HIV risk behaviors among MA-using MSM. Based on this information we concluded that a single session MI intervention would be feasible. In addition, evidence suggests that some efficacious interventions may not be effective in real-world settings due to low completion rates. 
Thus, despite evidence that longer interventions were likely to be more efficacious than a single session intervention, we were concerned that a multi-session intervention would not be used by local providers.

\section{Behavioral Determinants}

In the semistructured interviews with MA-using MSM, several men reported that they were unable to use MA and not engage in UAI. Other men felt that they could use condoms when having sex while using MA and these men indicated that they were not ready to stop using MA. Findings from the focus groups and the semistructured interviews suggested that for an intervention to be effective it would need to present men with a range of options for reducing their sexual risk behaviors associated with MA use. These findings suggested that an intervention could reduce HIV risk by reducing MA use, reducing sexual intercourse while using MA, or increasing condom use while using MA. Participants in the focus groups and semistructured interviews also felt that it would be difficult to get MA-using men to attend a multisession intervention and that the intervention should be delivered by a gay or bisexual man who had a history of MA use.

\section{Step 2. Matrices of Change Objectives}

After reviewing findings from the different inputs from the needs assessment, we selected reductions in UAI as our primary outcome. However, as noted, the needs assessment suggested that men should be presented with a range of options and that no single approach was likely to be effective for all men. Therefore, we chose three approaches for reducing UAI associated with MA use: (1) men could choose to use condoms consistently while engaging in anal intercourse while using MA, (2) men could choose to not have sex while using MA, and (3) men could choose to stop using MA. While these choices are presented as absolutes, it is important to remember that the primary outcome was to reduce UAI. As such the intervention could be considered effective if it resulted in risk reduction without completely eliminating risk.

\section{Step 3. Select Appropriate Theoretical Methods and Strategies}

As noted previously, findings from our needs assessment suggested that an intervention would need to (1) offer a menu of options for risk reduction, (2) be able to reduce both MA use and UAI, and (3) be brief.

Once we selected behavioral outcomes, we identified appropriate methods and strategies for changing the desired behaviors. As noted previously, the results of the literature review and focus groups suggested that many MA-using MSM are not ready to stop using MA and that many of them do not feel that they are able to reduce their sexual risk (e.g., use condoms or not have sex) while they are using MA. These findings suggested that an intervention that accomplished any of the following: (1) increased readiness to stop using MA; (2) increased motivation, and supported self-efficacy for condom use while using MA; (3) reduced the frequency of sex when using MA; or (4) led to cessation of MA use. would be appropriate. Because it seemed that reducing MA use may be essential for risk reduction in many men we selected motivational interviewing (MI) as our intervention approach. MI is a client-centered counseling style that brings about behavior change by working with clients to explore and resolve ambivalence [31,32]. The five central principles of MI are (1) using reflective listening to express empathy, (2) using reflective listening and objective feedback to develop discrepancy between client goals and current problem behavior, (3) avoiding arguments by giving the client the responsibility for the decision to change, (4) avoiding resistance instead of confronting or opposing it, and (5) supporting self-efficacy and optimism for change [31].

While MI was originally developed to reduce problem drinking [33], it has also been effective at reducing use of substances, including cocaine [34-36], marijuana [37], polysubstance use [38, 39], and amphetamines [40]. More recently, a single-session motivational intervention has shown promise for reducing ambivalence and increasing motivation to reduce sexual risk behaviors among people who are HIV positive [41]. Moreover, MI is a common element of several behavioral interventions focusing on MA users including the 16-session Matrix Model [42]. While this intervention has shown considerable promise, its length does not lend itself to use with out-of-treatment drug users in the community. Risk behaviors, barriers to change, and intervention characteristics and needs are shown in Table $\mathbf{1}$.

\section{Step 4. Design Intervention}

When this study started in 2006, there were few if any published reports of effective HIV risk reduction interventions for MA using MSM; therefore, we reviewed interventions for MSM and for MA users. Findings from the literature review suggested that multi-session interventions with a minimum exposure time of 4 hours over a period of at least 3 weeks are likely to be more effective in changing sexual behavior than very brief interventions [43]. Nonetheless, studies have also shown that brief interventions, such the brief intervention in Project RESPECT that consists of two 15 minute client-centered counseling sessions and the 2-session NIDA Standard intervention, which is cue-card based and lasts less than an hour can be as effective as many longer more intensive interventions in reducing HIV risk behaviors [44, 45]. Additional support for designing a brief intervention came from findings from the focus groups with providers, which suggested that many service providers may not have the resources to deliver labor intensive, multisession interventions. Moreover, findings from the focus groups and semistructured interviews with MA users suggested that many users would be unwilling to attend multisession interventions.

In response to these findings, we designed a singlesession MI intervention, which was divided into 8 sections that take a total of approximately 90 minutes to complete. As noted, the intervention presented men with the following options for reducing their HIV risk:
a. Cessation of MA use
b. Stop having sex while using MA
c. Always use a condom when having sex while using
MA

Additional details regarding the intervention are shown in Table 2. 
Table 1. Risk Behaviors, Barriers to Risk Reduction, and Preferred Intervention Characteristics

\begin{tabular}{|c|c|}
\hline $\begin{array}{l}\text { Unprotected anal intercourse is common among methamphetamine-using } \\
\text { MSM }\end{array}$ & Reduce unprotected anal intercourse \\
\hline \multirow[t]{2}{*}{$\begin{array}{l}\text { Methamphetamine-using MSM often engage in unprotected anal } \\
\text { intercourse with nonprimary partners when using methamphetamine }\end{array}$} & $\begin{array}{c}\text { Reduce unprotected intercourse with non-primary partners when using } \\
\text { methamphetamine }\end{array}$ \\
\hline & Reduce methamphetamine \\
\hline Men are not ready to reduce their methamphetamine use & Increase readiness to reduce methamphetamine use \\
\hline $\begin{array}{c}\text { Men do not feel that they are able to use condoms when they are using } \\
\text { methamphetamine }\end{array}$ & Increase self-efficacy for using condoms when using methamphetamine \\
\hline Men do not feel that they can use methamphetamine and not have sex & Increase self-efficacy for avoiding sex when using methamphetamine \\
\hline Intervention should offer options for reducing risk & $\begin{array}{c}\text { Develop an intervention that provides a menu of options for reducing sexual } \\
\text { risk associated with methamphetamine use }\end{array}$ \\
\hline $\begin{array}{l}\text { Many HIV prevention providers do not have the resources to deliver } \\
\text { multisession interventions that are delivered by highly trained } \\
\text { professionals }\end{array}$ & Develop a brief intervention that can be delivered \\
\hline
\end{tabular}

\section{Intervention Pretest and Refinement}

After we developed the intervention based on findings from the previous steps in the intervention mapping process, we pretested it with six current MA users. Findings from the pretest suggested that it would be too difficult and timeconsuming to address MA use and sexual risk in a single 90minute session. In response to this finding, although we continued to present men with a menu of options for change, men were allowed to pick only one option. Once a risk reduction option was picked then a plan for carrying through with the behavior change was developed.

\section{DISCUSSION}

Intervention mapping provides a useful, systematic approach to intervention development. However, we found that some steps in the process needed to be adapted to use the process for developing an intervention trial in the context of a funded research project.

The funding opportunity identified a general need for interventions to reduce HIV risk among MSM who use MA. Our review of the literature and our previous work with MSM in the area indicated that MA use among MSM is a problem and that it is associated with high risk sexual behavior. Moreover, our review of the literature and our previous work suggested that a brief MI intervention may be effective in reducing sexual risk and MA use among MSM.

As we collected and analyzed new data using focus groups and semistructured interviews we were able to specify the details needed to operationalize our intervention. We selected reducing or stopping MA use, not having sex while using MA, and using condoms when having sex while using MA as behavioral outcomes for the intervention. We also determined that a single-session intervention would be more acceptable than a multisession intervention. And finally, we determined to use MSM with a history of MA use as our interventionists.

The results of the pretest suggested that a single 90minute session provided insufficient time to work on reducing both MA use and sexual risk in most men. Therefore, we revised the intervention so that following the assessments of motivation to change MA use and sexual risk, clients were presented with an option of which issue they would prefer to change. Then efforts to enhance motivation to change focused on that behavior and the plan for change that was developed focused either on decreasing MA use, reducing the frequency of sex while using MA, or increasing condom when having sex while using MA. While this solution may have been less than optimal in terms of intervention efficacy, a priority of the study was to develop an intervention that could be used widely. While this approach may result in a somewhat less efficacious intervention, interventions that have a small effect on a large number of people may have as great or greater an impact on a population as interventions that have a large impact on a small number of people. Behavioral outcomes from the pilot study should provide some insight into the efficacy of the intervention described in this study.

\section{LIMITATIONS}

As noted previously, this intervention was developed in the context of a funded research project that was based on a proposal that was in response to a funding opportunity. Therefore, some decisions regarding the intervention were made prior to completion of all phases of the needs assessment. Accordingly we did not follow all of the steps in 
Table 2. Single-Session MI Intervention Content and Timing

\begin{tabular}{|c|c|c|}
\hline Section & Content/Activity & Length in Minutes \\
\hline 1 & $\begin{array}{l}\text { Introduction } \\
\text { Provide a brief introduction to orient the participant to the spirit of MI and briefly explain what will be covered during } \\
\text { the session }\end{array}$ & 5 \\
\hline 2 & $\begin{array}{l}\text { a. Review the client's patterns of methamphetamine use to ascertain the frequency and duration of use and the } \\
\text { amount of methamphetamine used and the route of administration (e.g., sniffed, smoked, injected). } \\
\text { b. Assess the physical, social, and emotional contexts in which methamphetamine is used. } \\
\text { c. Explore substance-free alternatives. }\end{array}$ & 5 \\
\hline 3 & $\begin{array}{l}\text { Patterns of methamphetamine use } \\
\text { Assess the patterns of sexual risk behavior with and without methamphetamine use: } \\
\text { a. types of sexual behaviors (e.g., insertive or receptive anal intercourse); } \\
\text { b. types of partners (e.g., main, casual); } \\
\text { c. frequencies of high-risk sexual activities; } \\
\text { d. contexts of high-risk sexual activities; and } \\
\text { e. attitudes toward HIV. } \\
\text { Assess contexts in which unprotected anal intercourse is most likely to occur. } \\
\text { a. Physical contexts } \\
\text { b. Social contexts } \\
\text { c. Emotional contexts }\end{array}$ & 10 \\
\hline 4 & 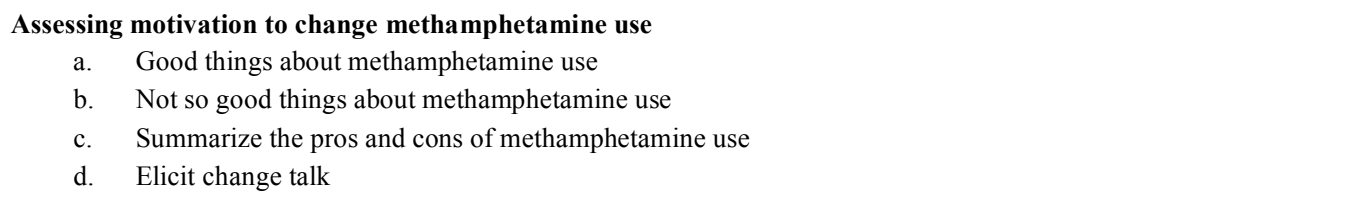 & 15 \\
\hline 5 & $\begin{array}{l}\text { Assessing motivation to change sexual risk behavior } \\
\text { a. Good things about unprotected anal sex with emphasis on sex while using methamphetamine or other drugs } \\
\text { b. Not so good things about unprotected anal sex } \\
\text { c. Summarize the pros and cons of unprotected anal sex } \\
\text { d. Elicit change talk }\end{array}$ & 15 \\
\hline \multirow[t]{2}{*}{6} & Enhancing motivation to change & 20 \\
\hline & $\begin{array}{l}\text { Changing Sexual Risk Behaviors } \\
\text { a. Identify the pros and cons to changing high-risk sexual behaviors. } \\
\text { b. Identify the pros and cons to staying the same (i.e. not changing). } \\
\text { c. Explore what might happen if changes are made. } \\
\text { Changing Methamphetamine Use } \\
\text { a. Identify the pros and cons to changing methamphetamine use. } \\
\text { b. Identify the pros and cons to staying the same (i.e., not changing). } \\
\text { c. Explore what might happen if changes are made. }\end{array}$ & \\
\hline 7 & $\begin{array}{l}\text { Planning for change } \\
\begin{array}{l}\text { a. Establish a plan for changing meth use and/or sexual risk behaviors. } \\
\text { b. Explore barriers to changing methamphetamine use and sexual risk behavior. } \\
\text { c. Emphasize personal power and self-efficacy (e.g., explore previous successful change attempts. } \\
\text { d. Imagine hypothetical situations } \\
\text { i. Situation for reducing sexual risk } \\
\text { ii. Situation for reducing methamphetamine use. }\end{array}\end{array}$ & 15 \\
\hline 8 & $\begin{array}{l}\text { Summary and closing } \\
\begin{array}{ll}\text { a. } & \text { Summarize high points of session } \\
\text { b. } & \text { Debrief } \\
\text { c. } & \text { Distribute HIV and methamphetamine education prevention materials } \\
\text { d. } & \text { Provide lists of referrals for substance and HIV }\end{array}\end{array}$ & 5 \\
\hline
\end{tabular}

the intervention mapping process exactly as they are specified in the intervention mapping protocol. Nonetheless we were able to follow most of the steps in the process in the order in which they are intended be conducted.

In addition, due to difficulties in recruiting MA-using MSM, the number of individual interviews and focus groups we conducted during the formative phase was insufficient to reach saturation on some concepts. In qualitative studies, it is preferable to continue data collection (i.e. focus groups and individual interviews) until saturation is reached and no new themes arise [46]. However, it was not feasible in this study to continue qualitative data collection until saturation was reached due to difficulties in recruiting MA-using MSM. 
While this situation was less than optimal, the effects were partially offset by the team's extensive previous experience working with MA and other stimulant users [29, 47, 48]. In addition, we had recently completed a number of qualitative interviews with MA-using MSM in the area as part of the formative phase of the NC-SATHCAP. Consequently, we were able to draw from multiple sources to inform our intervention. Nonetheless, this raises some difficult questions regarding how best to develop interventions for use in settings where specific risk groups are present in low concentrations. It may be more efficient to develop interventions in areas where the population of interest is more concentrated. However, doing so increases the risk of a mismatch between the resources required for the intervention and the resources that are available for delivering it in the setting of interest. It also may result in an intervention that may not be acceptable to the target population. For example, in some less urban settings limited public transportation, compared to what is available in major urban areas, may increase the burden of attending multiple intervention sessions.

\section{CONCLUSIONS}

Intervention mapping provides a flexible approach to the systematic development of behavioral interventions. Even when systematic approaches, such as intervention mapping, cannot be followed exactly they provide a useful tool for developing interventions. Systematic approaches take much of the mystery out of the process and may make it easier for intervention developers to explain the process to others. Intervention development may benefit from the use of systematic approaches whenever feasible. However, the process may need to be adapted to the local setting. In addition, intervention developers may need to strike a balance between intervention efficacy and intervention utility.

\section{ACKNOWLEDGEMENTS}

This research was supported by grant no. UR6 PS000310 from the U.S. Centers for Disease Control and Prevention. We thank Gordon Mansergh and Mahnaz Charania for their helpful suggestions and support through the course of the study. We would also like to thank our consultants, Michael Ross and Lisa Hightow for all of their help.

\section{REFERENCES}

[1] Shoptaw S. Methamphetamine use in urban gay and bisexual populations. Top HIV Med 2006; 14(2): 84-7.

[2] Colfax G, Coates TJ, Husnik MJ, et al. Longitudinal patterns of methamphetamine, popper (amyl nitrite), and cocaine use and highrisk sexual behavior among a cohort of San Francisco men who have sex with men. J Urban Health 2005; 82(1 Suppl 1): i62-70.

[3] Mansergh G, Colfax GN, Marks G, Rader M, Guzman R, Buchbinder S. The Circuit Party Men's Health Survey: findings and implications for gay and bisexual men. Am J Public Health 2001; 91(6): 953-8.

[4] Mattison AM, Ross MW, Wolfson T, Franklin D. Circuit party attendance, club drug use, and unsafe sex in gay men. J Subst Abuse 2001; 13(1-2): 119-26.

[5] Thiede H, Valleroy LA, MacKellar DA, et al. Regional patterns and correlates of substance use among young men who have sex with men in 7 US urban areas. Am J Public Health 2003; 93(11): 1915-21.
[6] Semple SJ, Zians J, Strathdee SA, Patterson TL. Sexual marathons and methamphetamine use among hiv-positive men who have sex with men. Arch Sex Behav 2009; 38(4): 583-90.

[7] Mimiaga M, Reisner S, Bertrand $\mathrm{T}$, et al. Crystal methamphetamine use and HIV/STI risk behavior among Massachusetts MSM: implications for intervention development. Ann Behav Med 2008; 35: S136-S.

[8] Halkitis PN, Shrem MT, Martin FW. Sexual behavior patterns of methamphetamine-using gay and bisexual men. Subst Use Misuse 2005; 40(5): 703-19.

[9] Halkitis PN, Parsons JT, Stirratt MJ. A double epidemic: crystal methamphetamine drug use in relation to HIV transmission among gay men. J Homosex 2001; 41(2): 17-35.

[10] Schwarcz S, Scheer S, McFarland W, et al. Prevalence of HIV infection and predictors of high-transmission sexual risk behaviors among men who have sex with men. Am J Public Health 2007; 97(6): 1067-75.

[11] Shoptaw S, Reback CJ. Associations between methamphetamine use and HIV among men who have sex with men: A model for guiding public policy. J Urban Health-Bull NY Acad Med 2006; 83(6): 1151-7.

[12] Menza TW, Hughes JP, Celum CL, Golden MR. Prediction of HIV acquisition among men who have sex with men. Sex Transm Dis 2009; 36(9): 547-55.

[13] Ostrow DG, Plankey MW, Cox C, et al. Specific Sex Drug Combinations Contribute to the Majority of Recent HIV Seroconversions Among MSM in the MACS. J Acquir Immune Defic Syndr 2009; 51(3): 349-55.

[14] Rusch M, Lampinen TM, Schilder A, Hogg RS. Unprotected anal intercourse associated with recreational drug use among young men who have sex with men depends on partner type and intercourse role. Sex Transm Dis 2004; 31(8): 492-8.

[15] Reback CJ, Larkins S, Shoptaw S. Changes in the meaning of sexual risk behaviors among gay and bisexual male methamphetamine abusers before and after drug treatment. AIDS Behav 2004; 8(1): 87-98.

[16] Molitor F, Truax SR, Ruiz JD, Sun RK. Association of methamphetamine use during sex with risky sexual behaviors and HIV infection among non-injection drug users. West J Med 1998; 168(2): 93-7.

[17] Paul JP, Stall R, Davis F. Sexual risk for HIV transmission among gay/bisexual men in substance-abuse treatment. AIDS Educ Prev 1993; 5(1): 11-24.

[18] Cohen CE, Giles A, Nelson M. Sexual trauma associated with fisting and recreational drugs. Sex Transm Infect 2004; 80(6): 46970.

[19] Stone E, Heagerty P, Vittinghoff E, et al. Correlates of condom failure in a sexually active cohort of men who have sex with men. $\mathrm{J}$ Acquir Immune Defic Syndr Hum Retrovirol 1999; 15; 20(5): 495501.

[20] Molitor F, Ruiz JD, Flynn N, Mikanda JN, Sun RK, Anderson R. Methamphetamine use and sexual and injection risk behaviors among out-of-treatment injection drug users. Am J Drug Alcohol Abuse 1999; 25(3): 475-93.

[21] Patterson TL, Semple SJ, Zians JK, Strathdee SA. Methamphetamine-using HIV-positive men who have sex with men: correlates of polydrug use. J Urban Health 2005; 82(1 Suppl 1): i120-6.

[22] Gorman M, Halkitis P. Methamphetamine and club drug use and HIV. Focus (San Francisco, Calif) 2003; 18(7): 5.

[23] Rawson RA, Simon SL, Ling W. If a US drug abuse epidemic fails to include a major east coast city, can it be called an epidemic? J Addict Dis 2002; 21(1): 1-4.

[24] Hirshfield S, Remien RH, Humberstone M, Walavalkar I, Chiasson MA. Substance use and high-risk sex among men who have sex with men: a national online study in the USA. AIDS Care 2004; 16(8): 1036-47.

[25] Sexton RL, Carlson RG, Leukefeld CG, Booth BM Methamphetamine use and adverse consequences in the rural southern United States: An ethnographic overview. J Psychoactive Drugs 2006: 393-404.

[26] Rhodes SD, Hergenrather KC, Yee LJ, Knipper E, Wilkin AM, Omli MR. Characteristics of a sample of men who have sex with men, recruited from gay bars and Internet chat rooms, who report methamphetamine use. AIDS Patient Care STDS 2007; 21(8): 57583 . 
[27] Bartholomew LK, Parcel GS, Kok G, Gottlieb NH. Planning health promotion programs: an intervention mapping approach. 2nd ed. San Francisco: Jossey-Bass 2006.

[28] Zule WA, Bobashev GV, Wechsberg WM, Costenbader EC, Coomes CM. Behaviorally bisexual men and their risk behaviors with men and women. J Urban Health 2009; 86 (Suppl 1): 48-62.

[29] Zule WA, Costenbader E, Coomes CM, et al. Stimulant use and sexual risk behaviors for HIV in rural North Carolina. J Rural Health 2007; 23 (Suppl): 73-8.

[30] Zule WA, Costenbader EC, Coomes CM, Wechsberg WM. Effects of a hepatitis $\mathrm{C}$ virus educational intervention or a motivational intervention on alcohol use, injection drug use, and sexual risk behaviors among injection drug users. Am J Public Health 2009; 99(Suppl 1): S180-6.

[31] Strauss A, Corbin J. Basics of qualitative research: techniques and procedures for developing grounded theory. $2^{\text {nd }}$ ed. Thousand Oaks: Sage 1998.

[32] Zule WA, Costenbader EC, Meyer WJ, Jr., Wechsberg WM. Methamphetamine use and risky sexual behaviors during heterosexual encounters. Sex Transm Dis 2007; 34(9): 689-94.

[33] Zule WA, Desmond DP. An ethnographic comparison of HIV risk behaviors among heroin and methamphetamine injectors. Am J Drug Alcohol Abuse 1999; 25(1): 1-23.

[34] Miller W, Rollnick S. Motivational interviewing: preparing people for change. New York: the Guilford Press 2002.

[35] Rollnick S, Miller W. What is motivational interviewing? Behav Cogn Psychother 1995; 23(4): 325-34.

[36] Miller WR. Motivational interviewing with problem drinkers. Behav Psychother 1983; 11(2): 147-72.

[37] Daley DC, Salloum IM, Zuckoff A, Kirisci L, Thase ME. Increasing treatment adherence among outpatients with depression and cocaine dependence: results of a pilot study. Am J Psychiatry 1998; 155(11): 1611-3.

[38] Donovan DM, Rosengren DB, Downey L, Cox GB, Sloan KL. Attrition prevention with individuals awaiting publicly funded drug treatment. Addiction 2001; 96(8): 1149-60.
[39] Stotts AL, Schmitz JM, Rhoades HM, Grabowski J. Motivational interviewing with cocaine-dependent patients: a pilot study. J Consult Clin Psychol 2001; 69(5): 858-62.

[40] Stephens RS, Roffman RA, Curtin L. Comparison of extended versus brief treatments for marijuana use. J Consult Clin Psychol 2000; 68(5): 898-908.

[41] Barrowclough C, Haddock G, Tarrier N, et al. Randomized controlled trial of motivational interviewing, cognitive behavior therapy, and family intervention for patients with comorbid schizophrenia and substance use disorders. Am J Psychiatry 2001; 158(10): 1706-13.

[42] Longshore D, Grills C, Annon K. Effects of a culturally congruent intervention on cognitive factors related to drug-use recovery. Subst Use Misuse 1999; 34(9): 1223-41.

[43] Baker A, Boggs TG, Lewin TJ. Randomized controlled trial of brief cognitive-behavioural interventions among regular users of amphetamine. Addiction 2001; 96(9): 1279-87.

[44] Rutledge SE. Single-session motivational enhancement counseling to support change toward reduction of HIV transmission by HIV positive persons. Arch Sex Behav 2007; 36(2): 313-9.

[45] Rawson RA, Marinelli-Casey P, Anglin MD, et al. A multi-site comparison of psychosocial approaches for the treatment of methamphetamine dependence. Addiction 2004; 99(6): 708-17.

[46] Herbst JH, Sherba RT, Crepaz N, et al. A meta-analytic review of HIV behavioral interventions for reducing sexual risk behavior of men who have sex with men. J Acquir Immune Defic Syndr 2005; 1; 39(2): 228-41.

[47] Kamb ML, Fishbein M, Douglas JM, et al. Efficacy of riskreduction counseling to prevent human immunodeficiency virus and sexually transmitted diseases: a randomized controlled trial Project RESPECT Study Group. JAMA 1998; 7; 280(13): 1161-7.

[48] Williams M, McCoy HV, Bowen A, Saunders L, Freeman R, Chen D. An evaluation of a brief HIV risk reduction intervention using empirically derived drug use and sexual risk indices. AIDS Behav 2001; 5(1): 31-43.

This is an open access article licensed under the terms of the Creative Commons Attribution Non-Commercial License (http: //creativecommons.org/licenses/by-nc/ 3.0/) which permits unrestricted, non-commercial use, distribution and reproduction in any medium, provided the work is properly cited. 